\title{
Transforming Culturally Sustaining Children's Books from the Exception to the Rule of Learning
}

\author{
Sabrina A. Brinson \\ Missouri State University, United States
}

\begin{abstract}
The interactive presentation demonstrates the multifaceted effectiveness of culturally sustaining children's books as curricula $(K-5)$ to facilitate inclusive education (e.g., genuine diversity, equity, inclusion, and social justice); counter "isms" like ableism, classism, colorism, racism, and sexism; bridge historical omissions of notable achievements by individuals from diverse populations; and facilitate students' holistic growth like cognitive, social, emotional, and moral milestones via active engagement in meaningful reading activities. Also, disseminated is a culturally sustaining clearinghouse of professional resources and a bibliography to train more trainers to generate ample, ongoing, equitable learning experiences with more students in homes, schools, and communities. Subsequently, students can be embraced with on-going opportunities to actively engage with culturally sustaining books to increase literacy/reading comprehension and counter aliteracy; advance other content areas like writing, social studies, science, art, and music; and nurture positive self-affirmations like self-worth and selfconfidence, as well as functional life skills like ingenuity and resilience.
\end{abstract}

\section{Introduction}

The How does it feel to be an afterthought? How does it feel to be a fleeting thought? Or how does it feel to be a superficial thought? Defining, confining, and marginalizing students continue to drive biased practices in education and stall reading proficiency for an alarming number of students. Brown [3] noted that colleges/universities have not fulfilled promises of diversity. It is common in many school communities regardless of their demographic makeup to focus primarily on one cultural group to the exclusion of others represented in the student/national population. When curriculum and instruction focus primarily on one cultural group to the exclusion of others represented in the student or national population, there can be a harmful educational impact on excluded student groups. Most schools influence their students' perceptions of who is entitled, and who have special privileges in society through curricula and instructional practices. To build a genuine community of learners, teachers must believe in the intellectual potential of all students and unequivocally accept responsibility to facilitate its realization without ignoring, demeaning, or neglecting students' ethnic and cultural identities. Academic success for diverse students is built on a base of cultural validation and strength, Krasnoff [7]. Teacher training should lead to mastery of course content and techniques to teach it meaningfully, with special attention to material in content standards, and include strategies tailored to diverse student populations and students with different learning styles, Spring [12]. This interactive presentation demonstrates the multifaceted effectiveness of culturally sustaining children's books as curricula $(\mathrm{K}-5)$ to facilitate genuine diversity, equity, inclusion, and social justice; counter "isms" such as ableism, classism, colorism, racism and sexism; bridge historical omissions; feature notable achievements of little known individuals from diverse populations; highlight ingenuity and resilience used to overcome obstacles; facilitate students' holistic growth (e.g., cognitive, social, emotional, and moral); and, actively engage students in books with opportunities to think critically, predict, and make intriguing discoveries about main characters through clues along the way.

\section{Demonstration of Culturally Sustaining Children's Books as Curricula}

Integrating reading featuring culturally sustaining books with other content areas like writing, social studies, science, art, and music can extend impactful learning (e.g., addressing social studies' themes like individual development and identity. Meet the Philadelphia Dolly Vardens: Inspired by the First African American Women's Professional Baseball Team, is the first title in the culturally sustaining series that I designed, Brinson [2]. It was showcased to demonstrate the use of culturally sustaining books to foster multiple facets of healthy development. For example, cognitive contributions include disseminating little-known historical achievements; facilitating active engagement in the learning process to reinforce reading components (e.g., fluency, comprehension, and baseball vocabulary is included in the book); and integrating reading and social studies). Also, resourceful characters, positive choices, and proactive resolutions to unfair dilemmas facilitate opportunities for more gains socially (e.g., 
effective communication and teamwork), emotionally (e.g., self-worth and self-confidence), and morally (e.g., developing a sound moral compass and strong work ethics). Namely, the book was written to heighten awareness about the first American women's professional baseball team, and all of the players were African American. Demonstrated is the effectiveness of strength that kept the Philadelphia Dolly Vardens in good stead during the reconstruction era. Highlighted are positive action steps in the face of unfair practices experienced by the main characters; and the importance of hard work and perseverance to achieve goals, "Strong has always been the real pretty." Plus, there are two big secrets to entice and actively engage readers in the book. The first secret illuminates the ingenuity and resilience that the Philadelphia Dolly Vardens utilized to achieve their athletic goals. The second secret, not revealed until the end, is designed to motivate re-reads for more fluency, comprehension, and vocabulary recognition, as well as readingextended activities to further engage students; nurture student ownership; and generate additional student-led inquiries and discoveries. Last reading teaser, by the end of the book readers will never look at a ball of yarn the same.

Reading for on-going meaningful experiences is the ultimate goal of utilizing culturally sustaining children's books as curricula. Gay [5] posited that culturally responsive books reflect knowledge and appreciation of different groups; and facilitate other benefits like reading; overall healthy development; abolishing discrimination; and, generating anti-bias practices. McCollin and O'Shea [9] found that the use culturally and linguistically diverse reading material facilitated reading comprehension, helped address phonological awareness gaps, and contributed to improved fluency. Titles are selected to advance cognitive development across content areas (e.g., culturally sustaining pedagogy, thematic units, standards-based instruction, and integrating reading with other content areas). Titles are selected to advance social development (e.g., active listening, cross-cultural respect, empathy, amiable interactions, proactive conflict resolution, and effective communication skills). Titles are selected to advance emotional development (e.g., gratified personal identity, positive self-image, adept mindfulness, and emotional well-being). Titles are selected to advance moral development (e.g., sound reasoning, positive problem-solving, and a strong moral compass). Titles are also selected to deactivate the disturbing practice of systematic marginalization in the publication arena. Cooperative Children's Book Center[4] reported that 3,115 children's books were published in 2020. However, the total number of children's books published about Black/African, Indigenous, Asian, Latinx, Pacific Islanders, and Arab characters were only 949 combined. Moreover, the total number of children's books written by Black/African,
Indigenous, Asian, Latinx, Pacific Islanders, and Arab authors were 877 books combined. Therefore, strong consumers of culturally sustaining children's books are a must to propel the powerful advocacy required for transformative changes of apropos practices among publishers. Moreover, titles are selected to demonstrate a flagship model of genuine diversity, equity, inclusion, and social justice-fair, balanced bibliography reflective of diverse populations (e.g., ethnicities, socioeconomic statuses, and disabilities) for use across multifaceted reading experiences. Comprehensively, titles proffer a wealth of information with culturally diverse characters, authors, and illustrators to neutralize systematic marginalization; accommodate collective/individual issues/needs; tap into collective/individual strengths//interests//aspirations; counter aliteracy; facilitate positive self-attributes; scaffold information; and maximize reading interests, reading experiences, and reading comprehension. Brinson [1] reported that multicultural literature is designed to give all children a SIP: Strong Self-worth, Information/Inspiration, and Pleasure. Literature experiences can make students feel good about themselves in every aspect of their development. Literature can stimulate a lifelong thirst for learning and satisfy inquiries via active engagement. Literature can tap into intelligences, strengths, and interests to advance thought-provoking competencies and achievements. Literature can also uplift students in a gale of positive energy, amiable perspectives, and good-humor.

\section{Accountability Action Steps}

Culturally sustaining children's books are utilized as curricula to embrace, validate, support, and advance the upward mobility of students in all communities (e.g., diverse populations of color, foster care, special needs, and under-served communities). Iwai [6] Educators should model positive attitudes toward diversity, plan effective instruction, and select highquality multicultural children's books for use across the curriculum, and collaborate with the community. Implementing the following three action steps is integral to transition the theory into effective practices. Foremost, invest in the on-going use of culturallysustaining children's books for students to become their best authentic selves via holistic healthy development (e.g., generate meaningful student-led reading experiences, nurture emotional wellness via a wealth of strong affirming characters reflective of diverse populations, and cultivate sound moral compasses via book experiences of positive problemsolving). Likewise, shatter walls of resistance and parades of only a handful of culturally sustaining children's books during holidays/heritage awareness months; and initiate a fair and balanced curricula via anti-bias practices that include-, affirm-, and uplift all students/families. Equally important, train more 
trainers to generate ample, on-going, equitable learning experiences with students/families in homes, schools, and communities. The Annie E. Casey Foundation [13] speaks to the importance of these action steps. As a nation we fail to provide children of color with the opportunities and support they need to thrive. In 14 states, the District of Columbia and Puerto Rico, children of color were the majority of the child population in 2019. Yet, states are failing to dismantle barriers that African-, Latino-, and Native American children especially encounter. National inequities are deep, systemic, and stubbornly persistent. The future success of our nation depends on our ability to ensure all children have the chance to be successful.

\section{Culturally Sustaining Pedagogy Tools to Train-the-Trainers}

Culturally authentic books written by authors and depicted by illustrators who are of the culture they are portraying are valuable inclusions because of the authentic, culturally conscious ideology provided. Moreover, said authors and illustrators should be expressly studied as part of the curricula Lohfink [8]. Multicultural literature can help students develop global awareness by introducing them to current cultural issues. When students vicariously experience the feelings and emotions of others through literature, they are encouraged to look critically at the world and gain a greater understanding of the global community, Monobe and Son [11]. Diverse book awards like the following are instrumental in selecting high-quality (e.g., well written), culturally sustaining children's books that can be utilized as curricula:

- American Indian Youth Literature Award recognizes the best writing and illustrations by and about American Indians.

- Américas Award for Children's and Young Adult Literature recognizes U.S. published children's and young adult books that authentically and engagingly portray Latin America, the Caribbean, or Latinos in the United States.

- Asian Pacific American Award recognizes outstanding books written by an individual of Asian or Pacific Islander descent.

- Carter G. Woodson Award recognizes exemplary books for children and young people.

- Coretta Scott King Award recognizes African American authors and/or illustrator whose books promote an understanding of the cultures of all people.
- Dolly Gray Children's Literature Award recognizes effective, enlightened portrayals of individuals with developmental disabilities in children's books.

- International Board on Books for Young Readers Award recognizes outstanding international books to promote international understanding.

- Robert F. Sibert Informational Book Medal is awarded annually to authors and illustrators of the most distinguished informational book published in the United States in English during the preceding year.

- Schneider Family Book Award honors an author or illustrator for a book that embodies an artistic expression of the disability experience for child and adolescent audiences.

- Young Readers Choice Award is distinctly different because the titles are nominated, and the winners are selected by children, teachers, parents and librarians.

The recommended clearinghouse of professional resources and bibliography of culturally sustaining books provided can be used to build/extend culturally impactful home/school/community libraries to eradicate diversity, equity, inclusion, and justice as an afterthought, a fleeting thought, or a superficial thought. McNair [10] reported that access to a diverse collection can support all students in finding titles that they can read and connect with in some aspect while affirming their own cultural identities and possibly developing important positive perspectives about others. Equally important, armed with ingenuity, resilience, self-worth, and other developmental milestones reaped from meaningful reading experiences with culturally sustaining books across content areas, students will have strength beyond measure to excel in all things positive.

\begin{tabular}{|l|}
\hline Clearinghouse of Professional Resources \\
\hline Acho, E. (2021). Uncomfortable conversations \\
with a black boy. Roaring Brook Press. \\
\hline Austin, K. (2019). Mindfulness for kids who worry: \\
Calming exercises to overcome anxiety. Rockridge \\
Press. \\
\hline Barboa, L. and Bradshaw, B. ( 2019 ). Autism- \\
What schools are missing: Voices for a new path. \\
Goldminds Publishing. \\
\hline Celano, M. and Collins, M. (2019). Something \\
happened in our town: A child's story about racial \\
injustice. (J. Zivion, Illus.). Magination Press. \\
\hline Davis, S., Jenkins, G., Hunt, Rameck, and Page, L. \\
F. (2002). The pact: Three young men make a \\
promise and fulfill a dream. Random House. \\
\hline
\end{tabular}


Dyson, M. E. (2018). What truth sounds like: Robert F. Kennedy, James Baldwin, and our unfinished conversation about race in America. St. Martin's Press.

Fuerte, G. (2020). The lying liar called racism. ( $L$. Ginting, Illus.). Real Life Bricks.

Garcia, L. (2020). What we believe: A black lives matter principles activity book (C. Davidson, Illus.). Lee and Low Books.

Grandhin, T. and Panek, R. (2014). The autistic brain: Helping different kinds of minds succeed. Mariner Books.

Harris, M. (2013). The girl who heard colors. (V. Brantley-Newton, Illus.). Nancy Paulsen Books.

Hill, H. (2007). Letters to a young brother: Manifest your destiny. Avery.

Hill, H. (2009). Letters to a young sister: DeFine your destiny. Avery.

Howard, T. C. (2019). Why race and culture matter in schools. Closing the achievement gap in America's classrooms. 2nd edition. Teachers College Press.

Hunt, R. (2009). We beat the street: Teacher guideRead, write, think, discuss, and connect. Novel Units.

Jones, D., and Hagopian, J. (2020). Black lives matter at school: An uprising for educational justice. Haymarket Books.

Laminack, L. L. and Kelly, K. (2019). Reading to make a difference using literature to help students speak freely, to think deeply, and take action. Heinemann.

Levy, A. (2017). What should Danny do? The power to choose. (M. Sadler, Illus.). Elon Books. Lewis, G. (2019). Scarlet Ibis. (S. Meyer, Illus.). Atheneum Books. Dolly Gray Children's Literature Award.

Lewis, J. , Andrew, A., and Powell, N. (2013). March One, Two, and Three: A graphic novel trilogy. (N. Powell, Illus.). Top Shelf Productions.

Medina, T. (2017). I am Alphonso Jones. (Robinson, S. and Jennings, J. Illus.). Tu Books.

Okorodudu, D. (2020). Black men in white coats: 100 rules for success! Independently Published.

Paris, D. and Alim, H. S. (2017). Culturally sustaining pedagogies: Teaching and learning for justice in a changing world. Teachers College Press.

Reynolds, J and Kendi, I. X. (2021). Stamped (for kids): Racism, antiracism, and you. Little Brown Books for Young Readers.

Sprunger, A. S. (2020). What is beautiful? (A. L. Snyder, Illus.). Parent Cue.

Weatherford, C. B. (2021). Unspeakable: The Tulsa Race Massacre. Carolrhoda Books.

Culturally Sustaining Bibliography

Titles to Demonstrate Genuine Diversity, Equity, Inclusion and Social Justice
Bolden, T. (2016). How to build a museum: Smithsonian's National Museum of African American history and culture ( T. Bolden, Illus.). Viking.

Brimmer, L. D. (2021). Without separation: Prejudice, segregation, and the case of Roberto Alvarez (M. Gonzalez, Illus.). Caulkins Creek.

Dunbar, E. A. (2020). Never caught, the story of Ona Judge: George and Martha Washington's courageous slave who dared to run away (K. Van Cleve, Illus.) Aladdin.

Gorman, A. (2021). The hill we climb: An inaugural poem for the country. Viking Books.

James, L. (2020). I promise (N. Mata, Illus.). HarperCollins.

Long, M. (2021). Kids on the march: 15 stories of speaking out, protesting, and fighting for justice. Algonquin for Young Readers.

Nelson, K. Heart and soul: The story of America and African Americans (K. Nelson, Illus.). Balzer + Bray.

Ramée, L. M. (2020). A good kind of trouble. Balzer + Bray.

Sorell, T. (2021). We are still here! Native American truths everyone should know (F. Lessac, Illus.). Charlesbridge.

Weatherford, C. B. (2022). Call me Miss Hamilton: One woman's case for equality and respect $(J$. Weatherford, Illus.). Millbrook Press.

Titles to Counter Ableism, Classism, Colorism, Racism and Sexism

Abdullah, S. (2014). My friend Suhana (A. Abdullah, Illus). Loving Healing Press.

Dee. J. (2019). The dirt girl (J. Dee, Illus.). Jodi Dee Publishing.

London, A. (2020). Journey of the freckled Indian: A Tlingit culture story (M. Rickert-Bolter and P. Singletary, Illus). Culture Story.

Millman, I. (2004). Moses sees a play (I. Millman, Illus.). Farrar, Straus and Giroux.

Mosca, J. (2017). The girl who thought in pictures: The story of Dr. Temple Grandin (D. Rieley, Illus.) Innovation Press.

Nolen, J. (2013). Hewitt Anderson's great big life (K. Nelson, Illus.). Simon and Schuster.

Nyong'o, L. (2019). Sulwe (V. Harrison, Illus.) Simon and Schuster.

Peete, H., Peete, R. E., and Peete, R. J. (2018).

Same and different: Teen life on the Autism express. Scholastic Press.

Perkins, M. (2007). Rickshaw girl (Jamie Hogan, Illus). Charlesbridge Press.

Watson, R. (2014). A place where hurricanes happen (S. Strickland, Illus.). Dragonfly.

Titles to Bridge Gaps Over Historical Omissions of Notable Achievements by Individuals from Diverse Populations

Barton, C. (2019). Whoosh! Lonnie Johnson's 


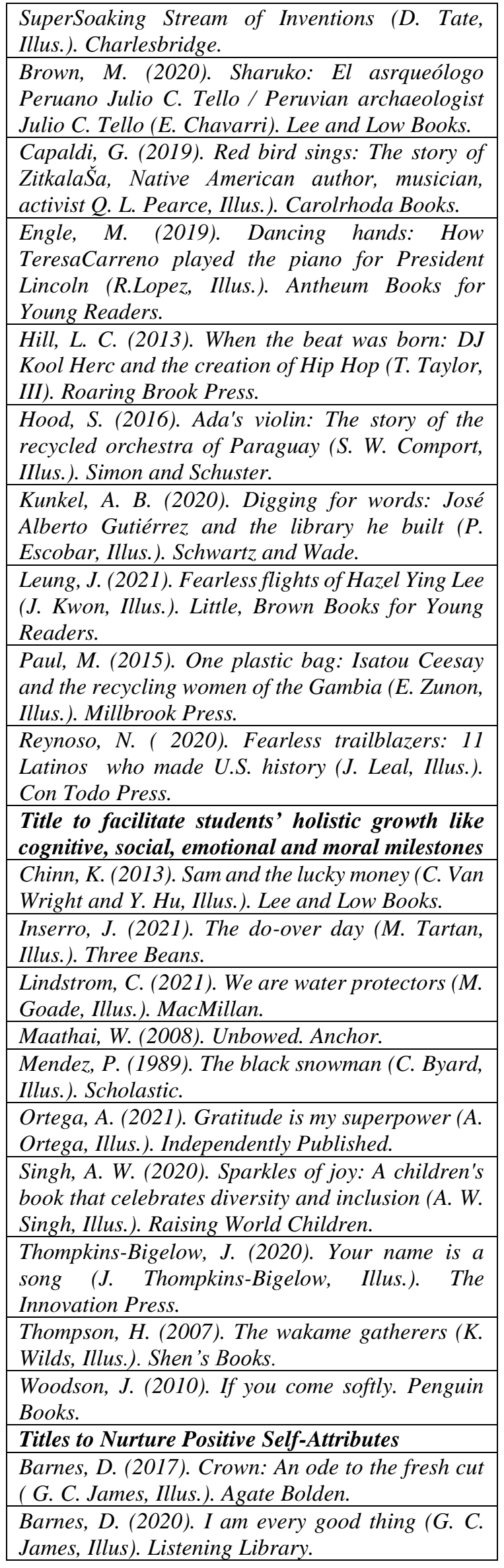

Brown, M. (2011). Marisol McDonald doesn't match / Marisol McDonald no combina ( $S$. Palacios, Illus.). Children's Book Press. Charles, T. (2020). All because you matter (B. Collier, Illus.). Orchard Books.

Curry, P. and Curry, J. (2019). Parker looks up: An extraordinary moment (B. Jackson, Illus). Aladdin.

Garcia, G. (2018). I can do hard things: Mindful Affirmations for kids (C. Russell, Illus.). Skinned Knee Publishers.

Ho, J. (2021). Eyes that kiss in the corners ( D. Ho, Illus.). HarperCollins.

Keller, T. (2021). When you trap a tiger (T. Keller, Illus.). Random House.

Noble, K. M. (2019). Fry bread: A Native American family story ( J. Martinez-Neal, Illus.). Roaring Brook Press.

Wilson, K. (2021). Mistakes are how I learn (K. Wilson, Illus.). Independently Published.

\section{Conclusion}

Audience members engaged in the presentation via culturally sustaining teaching demonstrations, related accountability action steps, and a Questionand-Answer Session. Also, to maximize home-, school-, and community learning, notable book awards were highlighted as culturally sustaining pedagogy tools, along with a culturally sustaining clearinghouse of professional resources, and a bibliography of culturally sustaining children's books to be utilized as curricula to advance genuine diversity, equity, inclusion, and social justice; eliminate "isms;" and facilitate students' holistic growth.

\section{References}

[1] Brinson, S. A. (2009). From Thunder Rose to When Marian Sang... Behold the power of African American female characters! Reading to encourage Self-worth, Inspire/Inform, and bring Pleasure. Young Children. 64(1), 26-31. Reprinted in the ERIC Document Reproduction Service No. ED EJ826243.

[2] Brinson, S. A. (2020). Meet the Philadelphia Dolly Vardens: Inspired by the first African American women's professional baseball team (M. Montgomery, Illus.). Amphorae Publishing.

[3] Browne, J. R. (2012). Walking the Equity Talk: A Guide for Culturally Courageous Leadership in School Communities. Thousand Oaks, CA: Sage Publications.

[4] University of Wisconsin-Madison Data on books by and about Black, Indigenous and People of Color published for children and teens compiled by the Cooperative Children's Book Center, School of Education, University of Wisconsin-Madison. https://ccbc .education.wisc.edu/litera 
ture-resources/ccbcdiersity-statist ics/books-by-about-pocfnn/. (Access Date: 3 September 2021).

[5] Gay, G. (2010). Culturally responsive teaching: Theory, research, and practice (2nd ed.). New York, NY: Teachers College Press.

[6] Iwai, Y. (2015). Using Multicultural Children's Literature to Teach Diverse Perspectives. Kappa Delta Pi Record, 51 (2), 81-86.

[7] Krasnoff, B. (2016). Culturally responsive teaching: A guide to evidence-based practices for teaching all students equally. Portland, OR: Education Northwest.

[8] Lohfink, G. (2010). The nature of Mexican American third graders' engagement with culturally relevant picture books. Bilingual Research Journal, 33 (3), 346-363. DOI: $10.1080 / 15235882.2010 .529346$

[9] McCollin, M., and O'Shea, D. (2005). Increasing reading achievement of students from culturally and linguistically diverse backgrounds. Preventing School Failure, 50 (1): 41-44.

[10] McNair, J. C. (2016). We need mirrors and windows: Diverse classroom libraries for K-6 students. The Reading Teacher, 70 (3), 375-381.

[11] Monobe, G., and Son, E. H. (2014). Using Children's Literature and Drama to Explore Children's Lives in the Context of Global Conflicts. The Social Studies, 105 (2), 69-74.

[12] Spring, J. (2013). Deculturalization and the struggle for equality: A brief history of the education of dominated cultures in the United States. New York: McGraw Hill.

[13] The Annie E. Casey Foundation. (2021). Reengaging students and closing the school-to-prison pipeline. Baltimore, MD: The Sentencing Project. www.aecf.org. (Access Date: 3 September 2021). 